\title{
DESENVOLVIMENTO DE ARGAMASSAS COLANTES UTILIZANDO RESÍDUOS DE BRITAGEM DE ROCHAS CALCÁRIAS.
}

\author{
Walney Gomes da Silva \\ IFRN - Campus Mossoró \\ Luiz Ailton de Araújo Souza \\ IFRN - Campus Mossoró. E-mail: luizailton@cefetrn.br \\ Marcos Daian Figueiredo da Silva \\ IFRN - Campus Mossoró. E-mail: marcosdaian@hotmail.com \\ Éverton de Souza Bezerra Júnior \\ IFRN - Campus Mossoró. E-mail: everton.veve@hotmail.com
}

\section{RESUMO}

As argamassas colantes têm grande emprego na construção civil, com isso este trabalho pretende avaliar a utilização de resíduos de britagem de rochas calcárias nas argamassas colantes, devido à sua grande utilização para fixar revestimentos cerâmicos sobre substratos. Além da caracterização de uma argamassa colante à base de resíduos, também se viu uma preocupação quanto à utilização de arisco na formulação da mesma, caso muito frequente em Mossoró e região. Assim, começou-se um trabalho de levantamentos bibliográficos, estudos dos materiais e formulação de traços, a fim de demonstrar novas modalidades de argamassas colantes, regidas pelas normas técnicas, que a venham contribuir para um amplo campo de materiais que antes eram desperdiçados. Sempre levando em conta questões financeiras de forma a que esta venha não só reduzir desperdícios, que iria ocupar localidades, já ou prestes a serem desmatadas, onde se poderia ser utilizadas para outros fins, no caso das já desmatadas, ou trazendo novas fontes de rendas mesmo com a conservação da mata original. Mas também, a questão de redução de custos que se vem a partir do momento em que se trabalha com um material amplamente abundante o que o torna de custo mais acessível, entrando ai dados de custobenefício.Deve-se ressaltar que toda formulação dessas argamassas são feitas de maneira a atender o mercado consumidor, em alternativas bem pensadas desde a escolha dos materiais a serem utilizados até os traços a serem trabalhados, onde destacamos suas escolhas pelas características regionais e já utilizadas na localidade em empresas que por aqui constam.

PALAVRAS-CHAVE: argamassa colante, resíduo de britagem, propriedades. 


\section{DESENVOLVIMENTO DE ARGAMASSAS COLANTES UTILIZANDO RESÍDUOS DE BRITAGEM DE ROCHAS CALCÁRIAS.}

\section{INTRODUÇÃO}

As argamassas colantes são utilizadas para a fixação de placas cerâmicas em substratos verticais e horizontais. Essas argamassas têm de atender a duas condições importantes, que são as de exposições durante a aplicação e as condições permanentes durante a vida útil dos revestimentos cerâmicos. A primeira dessas condições é conhecida como tempo em aberto, que é o período de tempo após o espalhamento da argamassa, tendo em vista a necessidade de utilizar aditivos para reter mais água, devido à demora na fixação das peças cerâmicas.

As argamassas colantes são normalizadas pela ABNT através da norma NBR 14081 (Argamassa colante industrializada para assentamento de placas cerâmicas Especificação), e são divididas nos seguintes tipos:

- AC I (Argamassa colante tipo I) - uso interno;

- AC II (Argamassa colante tipo II) - uso externo;

- AC III (Argamassa colante tipo III) - de alta resistência;

- AC III-E (Argamassa colante tipo III-E) - especial.

Este trabalho tem por função desenvolver argamassas colantes utilizando resíduos de britagem de rochas calcárias e avaliação da argamassa com areia argilosa, conhecida popularmente na região como arisco, atendendo as exigências das normas técnicas. Entra também a questão ambiental, ou seja, através da substituição da areia que é retirada dos leitos dos rios gerando o desmatamento da mata ciliar e erosão, por resíduo calcário, abundante na região, que antes seria rejeitado. Além do custo-benefício, que se traz na utilização de um material abundante logo barato.

A argamassa colante é um produto industrializado, composto basicamente por cimento Portland, areia com diâmetro até 0,50 mm e aditivos (HERCULES, 1997; OLMO, 1982; UNION CARBIDE 1997). Devido ao fato de ser aplicada em cordões de pequena espessura é determinante a presença dos aditivos retentores de água, para o seu o bom desempenho. Dentre os aditivos utilizados pode-se citar o HEC e o PVAc.

O HEC tem como principal propriedade a retenção de água. É um polímero de celulose natural modificada produzido pela eterificação parcial de alguns grupos hidroxila da celulose com o álcali celulose, que por sua vez, reage com o óxido de etileno para a formação do HEC (UNION CARBIDE, 1997).

O traço recomendado pelos fabricantes de aditivos retentores e por estudiosos varia entre 1:2 e 1:4 (cimento: areia, em massa) (HERCULES, [1997]; OLMO, 1982; UNION CARBIDE 1997). A granulometria e a forma dos grãos são também controladas. A forma dos grãos recomendada para a argamassa colante costuma ser lisa e arredondada, proporcionando melhor trabalhabilidade. A distribuição granulométrica é uma preocupação, e alguns fabricantes de argamassa complementam a granulometria com pó calcário (Póvoas e John1999). 
Uma das propriedades principais da argamassa colante é o tempo em aberto, definido como o período de tempo após o espalhamento da argamassa sobre o substrato, em que é possível o assentamento da cerâmica obtendo-se a resistência de aderência adequada, definida pela NBR-14.083 (ABNT, 1998) como maior ou igual a 0,5 MPa.

O tempo em aberto é considerado pelos textos normativos como um dos principais requisitos de desempenho da argamassa colante. Quando apresenta valores baixos, pode causar o descolamento de placas cerâmicas, principalmente em revestimentos externos, devido a diferentes fatores externos como variações de temperatura e velocidade de vento.

Segundo a Norma Brasileira devem ser feitos ensaios de verificação, como: o deslizamento, tempo em aberto teórico, resistência à tração, densidade da massa e resíduo em peneira \# 1,0 mm

\section{METODOLOGIA}

A realização da pesquisa começou com a coleta de materiais necessários para a confecção de tal argamassa, são eles: o cimento Portland tipo IV (pozolânico), argilomineral (arisco), areia fina, resíduo de britagem e aditivos.

Após a coleta dos materiais, foram realizados os ensaios de caracterização deles. Para os agregados (areia fina, argilomineral e resíduo de britagem) foram feitos ensaios de análise granulométrica, densidade real e aparente. Para o cimento, foram feitos os de densidade real e aparente e finura do cimento. Todos estes normatizados pela ABNT (associação brasileira de normas técnicas), sendo de fundamental importância para uma dosagem adequada dos traços de argamassa.

Nos resíduos e na areias serão determinadas suas características químicas, físicas e morfológicas através de ensaios de fluorescência de raios-X (XRF), difração de raios-X (XRD), análise térmica diferencial (DTA), granulometria a laser, superfície específica, microscopia óptica e microscopia eletrônica de varredura.

O planejamento para avaliar as propriedades das argamassas foi realizado variando-se a quantidade de argilomineral (arisco), areia e resíduo presente nas argamassas com traços em massa de 1:2, 1:4 e 1:5. A escolha dos traços foi determinada pela característica da região.

Com isso, através do índice de consistência da argamassa, podemos dosá-las com a quantidade de água necessária para que haja uma boa resistência e trabalhabilidade.

A seguir, na tabela 1, estão representados os traços, comumente empregados na região por apresentar boas características na sua composição e avaliação.

Após a dosagem, vários ensaios foram realizados, dentre eles resistência a tração na flexão e compressão, deslizamento da argamassa em superfície vertical e inclinada, resistência potencial de aderência à tração, tempo em aberto, execução do substrato padrão e aplicação de argamassa para ensaios. 
Tabela 1. Indicação dos traços.

\begin{tabular}{|c|c|c|}
\hline Id & Traços & Sigla \\
\hline 1 & $1: 2:$ Aditivos (cimento:areia) & CA12 \\
\hline 2 & 1:2:Aditivos (cimento: areia argilosa) & CAM12 \\
\hline 3 & $1: 2:$ Aditivos (cimento:Resíduo) & CR12 \\
\hline 4 & $1: 4:$ Aditivos (cimento:areia) & CA14 \\
\hline 5 & 1:4:Aditivos (cimento: areia argilosa) & CAM14 \\
\hline 6 & $1: 4:$ Aditivos (cimento:Resíduo) & CR14 \\
\hline 7 & $1: 5:$ Aditivos (cimento:areia) & CA15 \\
\hline 8 & 1:5:Aditivos (cimento: areia argilosa) & CAM15 \\
\hline 9 & 1:5:Aditivos (cimento:Resíduo) & CR15 \\
\hline
\end{tabular}

Para uma melhor avaliação da argamassa, esta é submetida a ensaios de retração da pasta, índices físicos e permeabilidade das pastas ao ar e água. O segundo é realizado de acordo co a ASTM C, que são os de teor de ar aprisionado, densidade da pasta no estado seco e úmido, e porosidade aparente.

Para a mistura dos materiais foi utilizada uma argamassadeira. Na moldagem dos corpos de prova, foi utilizado moldes cilíndricos de $5 \mathrm{~cm}$ de diâmetro e $10 \mathrm{~cm}$ de altura, com finalidade de medir a resistência à tração e compressão das argamassas. Distribuiu-se a argamassa em 3 camadas, sendo em cada aplicada 15 golpes. Após 24h, foram submersas em água até o dia de seu rompimento. Para cada traço, foram moldados 8 corpos de prova, sendo que cada duas amostras são rompidas após 3, 7, 14 e 28 dias de idade, este último caracterizando o fim de cura da argamassa, um para ensaio de resistência a tração e outro para compressão.

Após isso, o substrato padrão, é confeccionado, visando a elaboração de outros ensaios, como o de deslizamento, onde numa superfície vertical a argamassa desliza, sobre efeito da gravidade; tração na aderência, a qual se trata de medir a força de arrancamento do revestimento preso ao substrato, por unidade de área; e tempo em aberto, que se trata de medir o tempo de espera da argamassa pelo revestimento cerâmico.

\section{Materiais}

Para os corpos de prova e produção do substrato padrão, foram utilizados cimento Portland CP IV Z 32 RS doado pela Nassal; arisco; areia doada pela Bqmil; resíduo de britagem doado pela Bqmil; e aditivo. Na tabela 2 está representada as densidades dos materiais. Na tabela 3 está representada a finura do cimento e seu tempo de pega.

Tabela 2. Massa unitária e específica dos materiais utilizados

\begin{tabular}{|c|c|c|}
\hline Materiais & $\begin{array}{c}\text { Massa Unitária } \\
\left(\mathrm{g} / \mathrm{cm}^{3}\right)\end{array}$ & $\begin{array}{c}\text { Massa Específica } \\
\left(\mathrm{g} / \mathrm{cm}^{3}\right)\end{array}$ \\
\hline Cimento & 1,07 & 2,90 \\
\hline Areia fina & 1,60 & 2,63 \\
\hline Arisco & 1,56 & 2,62 \\
\hline Pó de brita & 1,63 & 2,65 \\
\hline
\end{tabular}


Tabela 3. Finura e tempo de pega do cimento.

\begin{tabular}{|c|c|}
\hline Material & Finura (\%) \\
\hline Cimento & 1,4 \\
\hline
\end{tabular}

Na tabela 4 está representada a composição granulométrica dos agregados, necessária para mostrar se é miúdo ou graúdo, indicar seus locais de utilização.

Tabela 4. Composição granulométrica dos agregados.

\begin{tabular}{|c|c|c|}
\hline Materiais & $\begin{array}{c}\text { Módulo de Finura } \\
(\mathbf{\%})\end{array}$ & $\begin{array}{c}\text { Diâmetro máximo } \\
\text { (mm) }\end{array}$ \\
\hline Areia fina & 2,1 & 1,2 \\
\hline Pó de brita & 2,6 & 4,8 \\
\hline Arisco & 2,6 & 2,4 \\
\hline
\end{tabular}

As curvas granulométricas ilustradas nas figuras 1,2 e 3, são respectivamente da areia fina, pó de brita e arisco.

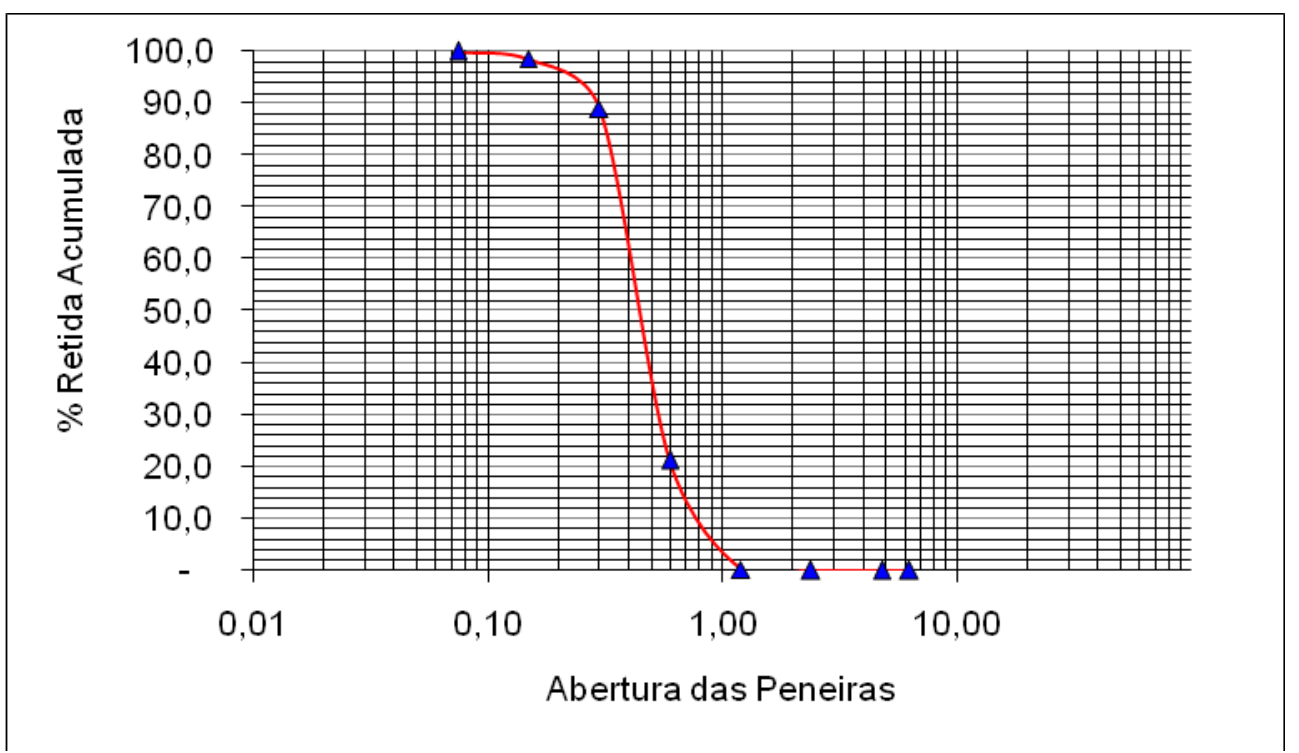

Figura 1 - Curva granulométrica da areia fina. 


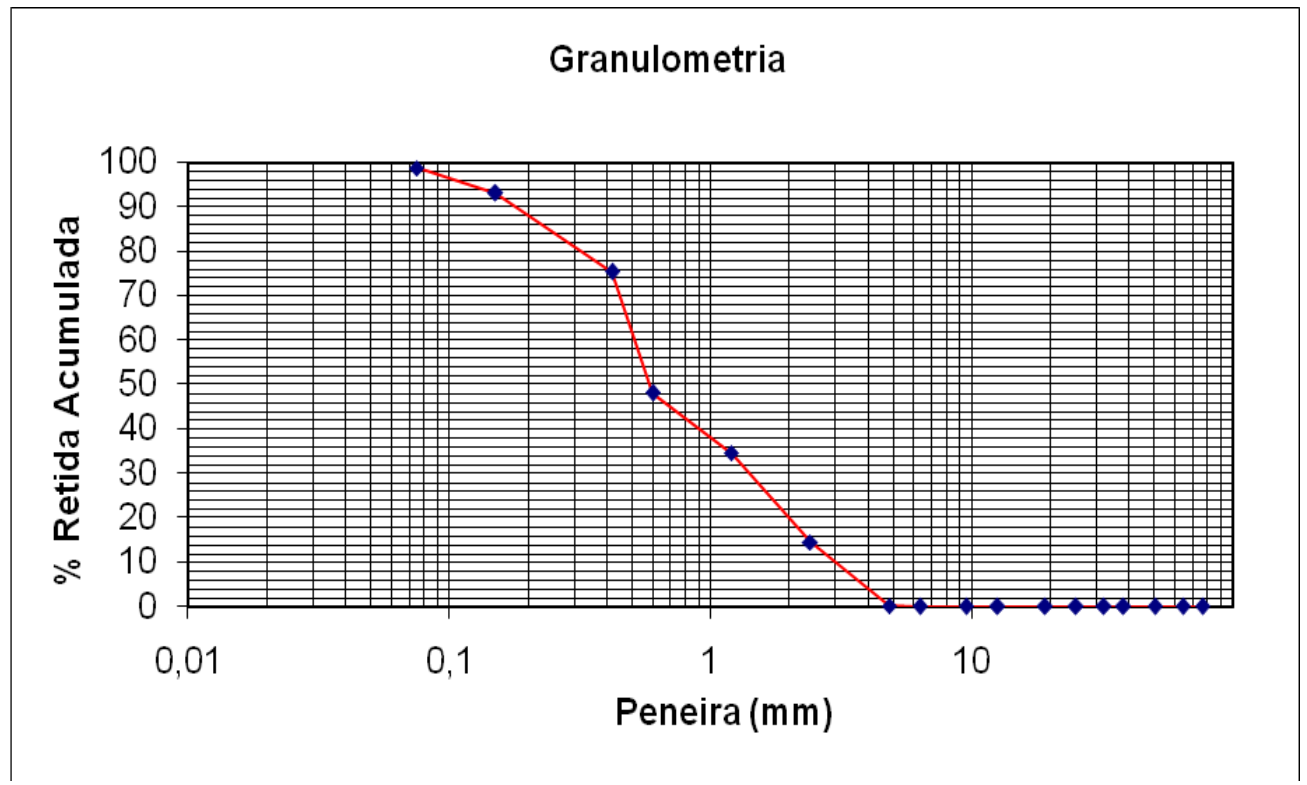

Figura 2 - Curva granulométrica do pó de brita.

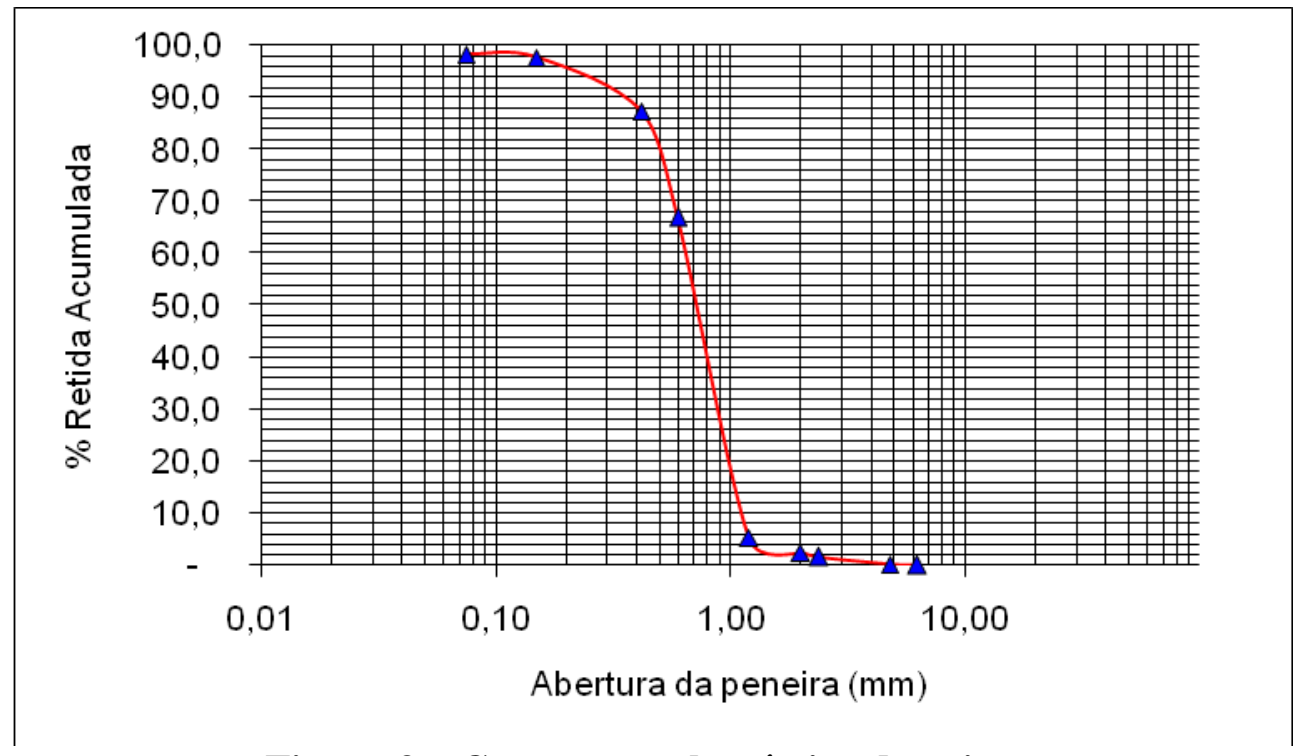

Figura 3 - Curva granulométrica do arisco.

\section{RESULTADOS}

A formulação da argamassa deu-se primeiramente pelo ensaio de índice de consistência padrão, que visa a determinação do fator água/cimento, onde a argamassa é colocada sobre uma mesa normatizada, específica ao ensaio, e nesta é aplicada 30 golpes em queda livre em 30 segundos, ocorrendo um achatamento dela. Adotamos como padrão o diâmetro de $16,5 \mathrm{~cm}$. 
Tabela 5. Fator água/cimento.

\begin{tabular}{|c|c|c|}
\hline Traços & Fator água/cimento & Sigla \\
\hline $1: 2$ areia & 0,46 & CA12 \\
\hline $1: 2$ arisco & 0,44 & CAM12 \\
\hline $1: 2$ pó de brita & 0,65 & CR12 \\
\hline $1: 4$ areia & 0,8 & CA14 \\
\hline $1: 4$ arisco & 0,68 & CAM14 \\
\hline $1: 4$ pó de brita & 1,23 & CR14 \\
\hline $1: 5$ areia & 0,95 & CA15 \\
\hline $1: 5$ arisco & 0,8 & CAM15 \\
\hline $1: 5$ pó de brita & 1,3 & CR15 \\
\hline
\end{tabular}

\section{Resistência à tração e compressão:}

São empregados apenas alguns traços com efeito de comparação. Para cada formulação dada, foram utilizados 8 corpos de prova cilíndricos $(5 \mathrm{~cm} \times 10 \mathrm{~cm})$ de cada traço utilizado, totalizando 56 destes. Com eles, foram determinadas as resistências à tração, por compressão diametral, e compressão, sendo rompidos após 3, 7, 14 e 28 dias. A tabela 6 apresenta as resistências à compressão após 7 e 28 dias. A tabela 7 apresenta as resistências à tração após 7 e 28 dias.

Tabela 6. Resistência à compressão.

\begin{tabular}{|c|c|c|}
\hline Traço & $\begin{array}{c}\text { Resistência à compressão } \\
(\mathrm{MPa}) \text { após 7 dias }\end{array}$ & $\begin{array}{c}\text { Resistência à compressão } \\
\text { (MPa) após 28 dias }\end{array}$ \\
\hline $1: 2$ areia & 14,78 & 35,97 \\
\hline $1: 2$ arisco & 7,69 & 30,42 \\
\hline $1: 2$ pó de brita & 15,39 & 27,56 \\
\hline $1: 4$ areia & 12,74 & 14,72 \\
\hline $1: 4$ pó de brita & 3,57 & 9,22 \\
\hline
\end{tabular}

Tabela 7. Resistência à tração.

\begin{tabular}{|c|c|c|}
\hline Traço & $\begin{array}{c}\text { Resistência à tração } \\
(\mathrm{MPa}) \text { após 7 dias }\end{array}$ & $\begin{array}{c}\text { Resistência à tração } \\
(\mathrm{MPa}) \text { após 28 dias }\end{array}$ \\
\hline $1: 2$ areia & 3,04 & 5,32 \\
\hline $1: 2$ arisco & 2,44 & 4,84 \\
\hline $1: 2$ pó de brita & 1,66 & 2,81 \\
\hline $1: 4$ areia & 1,76 & 2,7 \\
\hline $1: 4$ pó de brita & 1,18 & 1,96 \\
\hline
\end{tabular}

No momento, damos continuidade à montagem dos substratos sendo nele feitos diferentes ensaios que caracterizam a argamassa colante, como a resistência a aderência, deslizamento, tempo em aberto e retração da pasta. 


\section{CONCLUSÕES}

Na análise dos resultados até agora obtidos, pode-se verificar:

No ensaio do índice de consistência padrão da argamassa, obteve-se uma quantidade de água necessária para que ela adquira tanto resistência quanto trabalhabilidade boas, fatores importantíssimos para uma dosagem adequada.

No caso das resistências, tanto à tração quanto à compressão, a medida em que o tempo passa, verificou-se um aumento nelas. Outro parâmetro focalizado na observação deu-se a partir da quantidade de cimento no traço, ou seja, a medida em que há um aumento do aglomerante, há também um aumento nas resistências. No caso do pó de brita esse aumento ocorreu, em alguns casos significativamente, sendo que em relação a areia utilizada, sua resistência é inferior, isso se dá pela presença de material pulverulento no agregado, requerendo maior quantidade de água para a mesma consistência.

\section{REFERÊNCIAS BIBLIOGRÁFICAS}

ASSOCIAÇÃO BRASILEIRA DE NORMAS TÉCNICAS, Revestimento de Paredes e Tetos em Argamassas Inorgânicas; Especificação - NBR 13749. Rio de Janeiro, 1996.

Aguiar, Gerusa de, Estudos de argamassas com agregados contaminados por gesso de construção / Gerusa de Aguiar. Silva Maria de Souza Selmo - São Paulo: EPUSP, 2006 20 p. -(Boletim Técnico da Escola Politécnica da USP, Departamento de Engenharia de Construção Civil, BT/PC/438)

Almeida, Alessandra E. F. de Souza.;Sichieri, Eduvaldo. Estudo da Influência da Cura na Aderência entre Argamassas com Adições Poliméricas e Placas de Porcelanato. In: VI SIMPÓSIO BRASILEIRO DE TECNOLOGIA DAS ARGAMASSAS, 2005, p. 395-405.

Angulo, Sérgio Cirelli, Varabialidade de agregados graúdos de resíduos de contrução e demolição reciclados., V.M. John. - São Paulo: EPUSP, 2001.16 p. -(Boletim Técnico da Escola Politécnica da USP, Departamento de Engenharia de Construção Civil, $\mathrm{BT} / \mathrm{PCC} / 279)$

Brea, Fernando M..Resistência de Aderência e Tempo em Aberto com Adição de Éteres de Celulose. In: V SIMPÓSIO BRASILEIRO DE TECNOLOGIA DAS ARGAMASSAS, 2003, p. 507-517.

Campante, Edmilson Freitas, Projeto e execução de revestimento cerâmico. Baía, Luciana Leone Maciel. - São Paulo: 2003. -(Coleção primeiros passos da qualidade no camteiro de obras)

Costa, Marienne do Rocio de Mello Maron da Metodologia de caracterização de argamassas colantes / Marienne do Rocio de Mello Maron da Costa, Maria Alba Cincotto. -- São Paulo : EPUSP, 2007. 23 p. - (Boletim Técnico da Escola Politécnica da USP, Departamento de Engenharia de Construção Civil ; BT/PCC/449)

Della Pietra, Ivie Ferrai, Concreto com agregados graúdos reciclados com fribras de aço. Ivie Ferrari Della Peitra, Antonio Domingues de Figueiredo - São Paulo: EPUSP, 2006 - 
10 p. -(Boletim Técnico da Escola Politécnica da USP, Departamento de Engenharia de Construção Civil, BT/PC/424)

Kudo, Elizabete Kioko; Martin Neto, Márcio Luiz. Estudo dos Métodos de Determinação do Módulo de Deformação Estático e Dinâmico. In : IV SIMPÓSIO BRASILEIRO DE TECNOLOGIA DAS ARGAMASSAS, 2001, p.345-354.

Maranhão, Flávio; Costa e Silva,Angelo J.; Medeiros, Jonas S.; Barros, Mércia M. S. B. Influência do Tipo de Argamassas Colante e do Revestimento na Microestrutura e na Resistência de Aderência. In: V SIMPÓSIO BRASILEIRO DE TECNOLOGIA DAS ARGAMASSAS, 2003, p. 519-528.

Medeiros, Rita; Maranhão,FlávioL.;Barros, Mércia M. S. B. Estudo da Aderência de Argamassas Colantes em Placas de Gesso Acartonado. In: V SIMPÓSIO BRASILEIRO DE TECNOLOGIA DAS ARGAMASSAS, 2003, p. 529-539.

Oliveira, Juliana de; Silva, Denise Antunes da. Efeito da Saturação e Secagem póssaturação na Aderência entre Argamassa Colante e Porcelanato Uso de Areia Industrial de Basalto ema Argamassas de Revestimento. In: VI SIMPÓSIO BRASILEIRO DE TECNOLOGIA DAS ARGAMASSAS, 2005, p. 357-368.

Póvoas, Yêda Vieira, Tempo em aberto da argamassa colante: influência dos aditivos HEC e PVAc / Y.V. Póvoas, V.M. John. - São Paulo: EPUSP, 1999. p. -(Boletim Técnico da Escola Politécnica da USP, Departamento de Engenharia de Construção Civil, BT/PCC/241)

Póvoas, Yêda; Pileggit, Rafael;John,Vanderle; Análise do Filme Superficial da Argamassa Colante no Estado Fresco. In: VI SIMPÓSIO BRASILEIRO DE TECNOLOGIA DAS ARGAMASSAS, 2005, p. 369-381.

Sabbatini, Fernando Henrique, Projeto e execução de revestimento de argamassa. Baía, Luciana Leone Maciel. - São Paulo: 2000. - (Coleção primeiros passos da qualidade no camteiro de obras)

Saraiva, Ana Gabriela; Bauer, Elton; Bezerra, Luciana M.. Análise das Tensões entre Argamassas Colante e Placas Cerâmicas Submetidas a Esforços de natureza Térmica. In : IV SIMPÓSIO BRASILEIRO DE TECNOLOGIA DAS ARGAMASSAS, 2001, p.365376.

Silva, Narciso G;.Buest,Guilherme; Campiteli, Vicente. Argamassa com Areia Britada: Infleência dos Finos e da Forma das partículas. In: VI SIMPÓSIO BRASILEIRO DE TECNOLOGIA DAS ARGAMASSAS, 2005, p. 12-22.

Tristão, F. A.; Roman, H. R. Uso de Areia Industrial de Basalto ema Argamassas de Revestimento. In: VI SIMPÓSIO BRASILEIRO DE TECNOLOGIA DAS ARGAMASSAS, 2005, p. 59-64.

Tristão, F. A.; Roman, H. R. Uso de Areia Industrial de Basalto ema Argamassas de Revestimento. In: VI SIMPÓSIO BRASILEIRO DE TECNOLOGIA DAS ARGAMASSAS, 2005, p. 59-64. 